\title{
Políticas curriculares e identidades docentes disciplinares: a área de ciências da natureza e matemática no currículo do Ensino Médio do estado de São Paulo (2008-2011)*
}

\author{
Curriculum policies in the area of the nature science \\ and mathematics: relations between teacher narrative \\ and curricular discourse in the high school curriculum \\ of São Paulo state (2008-2011)
}

Maria Inês Petrucci-Rosa ${ }^{1}$

\begin{abstract}
Resumo: Este trabalho integra um projeto que investiga relações entre processos identitários docentes, reformas curriculares em nível de Ensino Médio e a noção de disciplina escolar. Focaliza, prioritariamente, a experiência curricular ocorrida no âmbito da Secretaria da Educação do Estado de São Paulo, com base nas políticas desenvolvidas desde 2008. Metodologicamente, a pesquisa se estruturou em dois momentos: (1) análise dos discursos presentes nos documentos curriculares da Proposta Curricular da SEE/SP acerca das identidades docentes; (2) realização e análise de entrevistas com cinco professores experientes da área das Ciências da Natureza e Matemática atuantes em escolas públicas paulistas. Como princípio teórico-metodológico, operou-se com os conceitos de narrativa e de mônadas. Da análise do material empírico, foi possível concluir que as identidades docentes expressas nos documentos curriculares são fragmentadas e contraditórias. Em relação às narrativas, foram percebidos usos e consumos ativos que rompem com a perspectiva de implementações acríticas.
\end{abstract}

Palavras-chave: Currículo. Ensino Médio. Escola pública. Ciências da natureza. Narrativa docente. São Paulo (Estado).

\begin{abstract}
This work is part of a project that investigates the relations among identity processes for teachers, curriculum reforms at high school and the notion of school discipline. It focuses primarily on the curricular experience that occurs within the Education Department of the State of São Paulo, from the policies pursued since 2008. Methodologically, the research is structured in two phases: (1) Analysis of the discourses present in the curriculum documents Curriculum Proposal of ESS / SP about teacher identities (2) Achievement and analysis of interviews with five experienced teachers in the area of Natural Sciences and Mathematics who work at public schools. As a theoretical-methodological principle, it was designed using the concepts of narrative and monads. From the analysis of empirical data, it was possible to conclude that teacher identities expressed in curriculum documents are fragmentary and contradictory. About the narratives - assets, uses and consumption were perceived that fracture the prospect of uncritical implementation.
\end{abstract}

Key words: Curriculum. High school. Public school. Life science. Teacher's narrative. São Paulo State.

"Esse artigo é fruto de resultados da pesquisa desenvolvida a partir do projeto "Formação docente em disciplinas escolares: políticas e identidades no contexto da cultura escolar", apoiado pelo CNPq nos processos U-475137/2008-6; PQ-306053/2009-8 e AT-504289/2010-1. Essa pesquisa também foi apresentada como parte integrante do painel "Identidade docente e formação disciplinar: a gestão do currículo e suas repercussões na prática docente a partir das políticas curriculares do Estado de São Paulo", no XVI Encontro Nacional de Didática e Prática de Ensino (ENDIPE), realizado na Unicamp, Campinas, em julho de 2012.

${ }^{1}$ Faculdade de Educação, Universidade Estadual de Campinas (Unicamp), Avenida Bertrand Russel, 801, Cidade Universitária Zeferino Vaz, CEP 13083-865, Campinas, SP, Brasil. Email: <inesrosa@unicamp.br> 


\section{Considerações iniciais: currículo e práticas cotidianas}

Este trabalho integra um projeto que investiga relações entre processos identitários docentes, reformas curriculares em nível de Ensino Médio e a noção de disciplina escolar. Assume-se que a configuração das disciplinas escolares está também fortemente ligada a processos identitários docentes, visto que há mais de cinquenta anos, no Brasil, programas de formação de professores licenciam profissionais da educação para atuarem em disciplinas escolares específicas correspondentes ao conjunto das atividades curriculares a serem desenvolvidas na escola básica. Nesse sentido, se acaso ou deliberadamente, programas de formação docente transformarem as marcas identitárias profissionais de seus egressos, novos arranjos disciplinares poderão também ser dinamizados no currículo da escola básica.

Na configuração do currículo do Ensino Médio brasileiro, há disciplinas que se estabeleceram, como é o caso de: Língua Portuguesa, História, Geografia, Física, Química, Biologia, Matemática e Educação Física. Todas estas já estão presentes há bastante tempo no currículo do Ensino Médio Brasileiro, sendo que algumas delas passaram por uma sequência de estágios. De acordo com a hipótese formulada por Goodson (1995), elas partem de um momento de marginalidade com um status inferior no currículo, passam para um estágio utilitário e, finalmente, alcançam uma definição como disciplina, que se configura a partir de um conjunto exato e rigoroso de conhecimentos. No período dos últimos oitenta anos, considerando como ponto de partida a Reforma Francisco Campos, realizada em 1931, outras disciplinas oscilaram sua permanência no currículo do Ensino Médio, como: Artes, Filosofia, Sociologia, Religião e Inglês, ou, pelo menos, tiveram flutuações importantes em sua carga horária.

Para autores que se inspiram em Goodson (1995), os fatores que interferem nas mudanças curriculares podem ser classificados em internos e externos. Os fatores internos dizem respeito às condições de trabalho na própria área, tais como: o surgimento de diferentes grupos de liderança intelectual, a criação de centros acadêmicos de prestígio atuando na formação de seus profissionais, a organização de associações profissionais, e a política editorial na área. Já os fatores externos estariam relacionados à política educacional e aos contextos econômico, social e político mais amplos. Moreira e Ferreira (2001) explicam que o peso de todos esses fatores depende da tradição da disciplina - prestígio acadêmico e tempo de existência - e do nível de organização de seus profissionais. Tal organização se expressa tanto nas associações acadêmicas quanto nas publicações e política editorial da área. Depende, também, das condições objetivas do lugar ou país, tais como o seu regime político e a estrutura de seu sistema educacional. Assim, é possível inferir que, quanto maior a maturidade de uma disciplina, maior o peso dos fatores internos. Esse peso também aumenta em proporção direta com a descentralização do sistema educacional. Por outro lado, o peso dos fatores externos pode ser mais significativo em países que passam por processos acelerados de transformações.

Há, no entanto, disciplinas escolares cujas carreiras científicas estão presentes no interior das universidades, que parecem sobreviver, permanentemente, nos currículos escolares, o que faz com que: "As disciplinas escolares acabam sendo vistas como disciplinas científicas adaptadas para fins de ensino, não se considerando o processo de recontextualização do conhecimento escolar" (MOREIRA; FERREIRA, 2001, p. 3).

O estudo das disciplinas e dos saberes escolares tem sido considerado fundamental para se compreender o papel dos contextos culturais na definição daquilo que deve ser ensinado na 
escola; e, por outro lado, o papel da escola na produção e na reelaboração do conhecimento, sobretudo, por meio dos processos de didatização.

Para Forquin (1992), esse campo de pesquisa possibilita obter informações acerca da seleção cultural que faz a escola, identificando o que é, em determinada época, compreendido como o que deve ser ensinado. [...] captar elementos que, em um conflituoso percurso de conquista de legitimidade de uma ou de outra disciplina curricular, mostrem a conquista de um estatuto, a briga por recursos, as delimitações territoriais no interior do currículo escolar, os espaços nos horários, etc. (SOUZA JÚNIOR; GALVÃO, 2005, p. 393)

As disciplinas escolares não se estabelecem no currículo escolar de maneira pacífica, conformando-se às orientações oficiais, mas, ao contrário, guardam relações conflituosas com teorizações acadêmicas e recomendações oficiais, ora acatando-as, ora resistindo a elas, ora reformando-as ou deformando-as.

Para Goodson (1995), a História das Matérias Escolares, compondo a área da História do Currículo, propõe-se a penetrar em um campo que os historiadores se mostram inclinados a ignorar: os conteúdos escolares, os métodos de ensino e os percursos de estudo, buscando nos processos internos da escola (caixa-preta) pistas para analisar as complexas relações entre escola e a sociedade, inclusive enfatizando como as escolas tanto refletem como refratam as definições da sociedade acerca dos conhecimentos culturalmente válidos. (SOUZA JÚNIOR; GALVÃO, 2005, p. 394)

Lopes (2005), com base em princípios foucaultianos e em contribuições de Stephen Ball e Basil Bernstein (1996, 1998 apud LOPES, 2005, p. 264), desenvolve uma análise acerca dos múltiplos discursos que se hibridizam na construção das disciplinas escolares. De acordo com as concepções teóricas, relativas às disciplinas escolares, a autora define as disciplinas, de forma geral, como saberes com bases epistemológicas mais ou menos explícitas, porém não são essas bases que definem a concepção de disciplina escolar. As disciplinas escolares atendem a finalidades sociais decorrentes do projeto social da escolarização, não se constituindo em simples reprodução de divisões de saberes do campo científico.

Os grupos sociais, entre eles os grupos disciplinares, atuam no sentido de construir novos sentidos para os textos oficiais e/ou reforçar sentidos estabelecidos previamente, acentuando o caráter híbrido das propostas curriculares. Compreender os sentidos que são produzidos por esses grupos nas políticas curriculares e os processos de legitimação associados a essas políticas permite entender alguns dos mecanismos que efetivamente condicionam a constituição do conhecimento escolar. (LOPES, 2005, p. 275) 
Entende-se aqui, também, a disciplina escolar como uma tecnologia de organização curricular constituída a partir de discursos híbridos e recontextualizados (LOPES, 2005), o que vem ao encontro daquilo que pode ser chamado de currículo loteamento (PETRUCCI-ROSA, 2007).

As políticas curriculares para Ensino Médio, no período pós-anos 1990, poderiam surtir efeitos de circularidade, desestabilizando o currículo loteamento, no contexto dos fazeres cotidianos escolares, à medida que defendem a interdisciplinaridade como um dos eixos didáticos-metodológicos da ação pedagógica. Para essa proposição, a imagem de um currículo diáspora, vivenciado pelos professores que se "aventuram" em experiências interdisciplinares, é proposta por Petrucci-Rosa (2007).

\section{Um recorte: o caso paulista}

Neste trabalho, o foco de investigação está no Currículo do Estado de São Paulo em relação ao Ensino Médio e, em particular, com a chamada área das Ciências da Natureza e Matemática. Para isso, são articuladas as noções teóricas de identidade (HALL, 2003), de cotidiano (CERTEAU, 1994) e de narrativa (BENJAMIN, 1994a, 1994b).

No final dos anos 1990, em âmbito federal, foram publicados os Parâmetros Curriculares Nacionais para o Ensino Médio (PCNEM) (BRASIL, 1999), como parte de um conjunto de textos que já vinham sendo produzidos no bojo de reconfiguração das políticas educacionais movimentadas pelo governo Fernando Henrique Cardoso (1995-2002). Os PCNEM traziam a noção de competências e habilidades como figura central do novo currículo concebido para o Ensino Médio, com uma articulação clara entre educação e o mundo do trabalho.

Iniciou-se uma nova fase da história do ensino secundário no país, com a tentativa de uma afirmação de identidade pedagógica com foco na formação para a vida, incluindo, aí, as demandas de formação de um novo trabalhador, mais eclético, flexível e autônomo. Nesse documento, propõe-se uma matriz disciplinar para o currículo delimitada por áreas, definindo-se aí três grandes áreas: as Linguagens, as Ciências Humanas e as Ciências da Natureza e Matemática².

Os autores dessa proposta na área de Ciências da Natureza são quase todos os mesmos, ou são do mesmo grupo político daqueles que elaboraram a Proposta Curricular do Estado de São Paulo (SÃO PAULO, 2008). Os PCNEM (BRASIL, 1999) trazem, ainda, dois eixos didático-metodológicos: a contextualização e a interdisciplinaridade, com os quais todo o trabalho pedagógico nas disciplinas deveria se organizar.

A partir de 2007, a Secretaria da Educação do Estado de São Paulo começa a contratar equipes de especialistas em importantes universidades públicas para redigir um documento curricular paulista, que pudesse dinamizar os contextos de influência e da prática trazendo transformações para o sistema educacional estadual. De acordo com informações que constam no site São Paulo Faz Escola³, a nova Proposta Curricular surge a partir dos resultados

\footnotetext{
${ }^{2}$ No atual currículo do Ensino Médio, também definido pelas Diretrizes Curriculares Nacionais para o Ensino Médio, publicadas em 2012, a Matemática compõe uma quarta área curricular, separando-se das Ciências da Natureza. ${ }^{3}$ Disponível em: <http://www.educacao.sp.gov.br/portal/projetos/sao-paulo-faz-escola>. Acesso em: 10 jun. 2014.
} 
do Sistema de Avaliação da Educação Básica (SAEB), do Exame Nacional do Ensino Médio (ENEM) e de outras avaliações que levaram o governo paulista a estabelecer dez metas para a Educação até 2010.

De forma articulada, propõe uma base curricular comum para todo o Estado. Depois desse primeiro momento, a Secretaria da Educação do Estado de São Paulo fez um levantamento na rede de ensino em busca de experiências exitosas junto a professores, coordenadores e diretores de escola. No início de 2008, a Secretaria elaborou o Jornal do Aluno, que foi utilizado por toda a rede durante 42 dias, com conteúdos que propiciavam atividades de recuperação em Português e Matemática. Participaram desse processo cerca de 3,6 milhões de alunos. Além do Jornal do Aluno, foi criada, também, a Revista do Professor, que depois foi denominada de Caderno do Professor, organizado e publicado para todas as disciplinas escolares do currículo do II Ciclo do Ensino Fundamental ( $5^{\circ}$ ao $9^{\circ}$ ano) e Ensino Médio.

A partir de 2008, o material denominado Caderno do Professor é distribuído para todas as escolas, sempre disciplinarmente, um para cada bimestre, ou seja: quatro exemplares no ano. Seu conteúdo abrange sequências didáticas e sugestões de trabalho, nas quais o professor pode se basear para desenvolver suas aulas. Durante esse mesmo ano, os alunos foram submetidos ao Sistema de Avaliação do Rendimento Escolar do Estado de São Paulo (SARESP), os Cadernos foram reformulados e, no site São Paulo Faz Escola, considera-se que, no início de 2009, o currículo já estaria consolidado.

Com tais considerações a respeito da emergência do Currículo do Ensino Médio do Estado de São Paulo, que define o escopo desta pesquisa delimitado no período entre 2008 e 2011, são apresentadas, a seguir, as assunções teórico-metodológicas definidas para este trabalho.

\section{Percurso teórico-metodológico da pesquisa}

Nas escolhas necessárias para a constituição do percurso teórico-metodológico, são importantes as considerações de Marin (2002), que aponta:

A perspectiva cultural parece decisiva para analisar as significações como sistema, inter-relacionando-as, nos levando a afirmar que a análise das práticas discursivas de professores [...] constituem exemplos de estudos de práticas que compõem a cultura docente. [...] Velhas identidades de professores estão sendo superadas e vêm sendo substituídas? Penso que sim, em parte e em parte penso que não. Devem-se detectar nas práticas de professores, e em suas significações, os indícios de sujeitos iluministas, sociológicos e pós-modernos no que tange à docência. (MARIN, 2002, p. 70)

Marin (2002) refere-se a S. Hall (2003 apud MARIN, 2002, p. 69), quando esse propõe três conceitos de identidade que permeiam processos socioculturais. O primeiro está relacionado ao sujeito do Iluminismo, cujo centro consistia num núcleo interior, que emergia, pela primeira vez, quando o sujeito nascia e com ele se desenvolvia, ainda que permanecendo essencialmente o mesmo - contínuo ou "idêntico" a ele - ao longo da existência do indivíduo. O centro essencial 
do eu era a identidade de uma pessoa (HALL, 2003, p. 10). Além disso, o sujeito do Iluminismo se constitui como um "indivíduo totalmente centrado e unificado, dotado de capacidades de razão, consciência e ação” (HALL, 2003, p. 11).

Essa concepção, no entanto, foi sendo contestada à medida que a sociedade foi se tornando mais complexa, adquirindo um caráter mais coletivo e social. A demanda da democracia moderna "transformou o empreendedor individual em conglomerados empresariais da economia moderna. O cidadão individual tornou-se enredado nas maquinarias burocráticas e administrativas do estado moderno" (HALL, 2003, p. 30). Nessa perspectiva, surge o sujeito sociológico: “[...] cujo núcleo interior do sujeito não era autônomo e auto-suficiente, mas era formado na relação com 'outras pessoas importantes para ele', que mediavam para o sujeito os valores, sentidos e símbolos - a cultura - dos mundos que ele/ela habitava” (HALL, 2003, p. 11).

Esse autor traz, nessa concepção, a assunção de que há um elo entre o mundo interior e o exterior, e esse elo é a identidade que se torna permeada pela presença do Outro. Esse Outro traz consigo as estruturas da sociedade, os símbolos da cultura em que vivem/ convivem esses sujeitos. Nessa interação, ambos se constituem, se unificam, "ficam costurados" à estrutura.

A identidade de cada um é permeada pela do outro. Nos discursos que ambos vão entrelaçando com outros e mais outros, os processos de identificação vão tornando essa identidade - anteriormente imaginada como única, fixa, centrada - em heterogênea, múltipla, perpassada por diferentes interpelações. Tais discursos podem chegar por meio das multiculturalidades geradas pelos processos de descolonização, pelas mídias, pelas possibilidades de comunicação planetária via Internet. Nessa perspectiva, surge a ideia de identidade ligada a um terceiro conceito, denominado por Hall (2003) como o sujeito pós- moderno. Dessa forma, podemos compreender que:

As identidades não são unificadas; que elas são na modernidade tardia, cada vez mais fragmentadas e fraturadas; que elas não são nunca, singulares, mas multiplamente construídas ao longo de discursos, práticas e posições que podem se cruzar ou ser antagônicos. As identidades estão sujeitas a uma historicização radical, estando constantemente em processo de mudança e transformação. (HALL, 2003, p. 108)

Discutindo a formação docente e suas identidades, Marin (2002, p. 70) indaga: “Quando nos voltamos para os professores e os cursos para sua formação, é muito pertinente perguntar: Velhas ou novas identidades? O que sabemos sobre professores nessas perspectivas de análise? Penso que muito pouco." Tal inquietação é aqui também compartilhada, o que define o desenho teórico-metodológico da investigação a ser aqui apresentada.

Opera-se com a noção de identidade, conforme propõe S. Hall (2003), com a compreensão de que processos de descentramento são marcas do mundo contemporâneo. Para o autor, a identidade fixa, una, indivisível é pura fantasia, visto que, nas relações sociais, processos de interpelação são vários e contraditórios, produzindo fragmentações e descentramentos no campo das identidades culturais (HALL, 2003). Nessa perspectiva, a identidade cultural, no mundo contemporâneo, retrata processos impregnados de ambiguidade e desestabilização. Não se trata do apagamento daquilo que cada um se tornou ao se identificar com uma outra cultura, mas, sim, de assumir que múltiplas interpelações emergem constantemente e que a manutenção 
do sujeito uno e centrado acaba por se tornar uma remota possibilidade. Hall também afirma que o nosso tempo é o tempo das culturas cada vez mais híbridas. Ao se referir às identidades culturais, afirma:

Elas carregam os traços das culturas, das tradições, das linguagens e das histórias pelas quais foram marcadas. A diferença é que elas não são e nunca serão unificadas no velho sentido, porque elas são, irrevogavelmente, o produto de várias histórias e várias culturas interconectadas, pertencem a uma e ao mesmo tempo a várias casas. (HALL, 2003, p. 88-89)

Do ponto de vista teórico, assume-se a noção de disciplina escolar como campo cultural. Ser professor de uma disciplina escolar significa carregar consigo uma bagagem cultural, constituída por jogos simbólicos, linguagem específica e formas peculiares de compreender o mundo e a vida. A identidade docente na escola contemporânea, cada vez mais interpelada pelos discursos de integração, tem se desdobrado fragmentada, à medida que o hibridismo cultural também se instala nas práticas escolares (PETRUCCI-ROSA, 2007).

Esse trabalho de pesquisa organizou-se em dois momentos ${ }^{4}$ : (1) A análise dos documentos curriculares da Proposta Curricular da Secretaria de Educação do Estado de São Paulo, mais notadamente, o material didático, e (2) As entrevistas realizadas com professores experientes do Ensino Médio que estão/estavam trabalhando com o referido currículo. Como material empírico, foram examinados 16 Cadernos do Professor, sendo quatro de cada disciplina, que são parte integrante da Proposta Curricular para o Ensino Médio do Estado de São Paulo, das disciplinas Biologia, Física, Matemática e Química, que estão inseridas nas áreas de Ciências da Natureza e Matemática. Além disso, foi analisada, também, a Proposta Curricular do Estado de São Paulo - Ensino Médio: Biologia / Física / Matemática / Química, (SÃO PAULO, 2008), presente no site São Paulo Faz Escola ${ }^{5}$.

\section{Análise dos textos curriculares representados pelos Cadernos do Professor}

As Propostas Curriculares de Biologia e Química são textos constituídos de 56 páginas cada uma e as de Física e Matemática de 64 páginas cada; os conteúdos das primeiras quarenta páginas são iguais para todas as Propostas, exceto com relação à ordem de alguns temas, todas distribuídas em uma Apresentação, onde se discutem os principais pressupostos da Proposta; três seções contemplando as áreas curriculares do Ensino Médio e, por fim, cada Proposta possui uma parte específica para falar dos conteúdos de cada disciplina. Na parte específica de cada Proposta, estão alguns temas que explicam e justificam a importância da disciplina e seus conteúdos; a ordem e os títulos das disciplinas de Biologia, Química e Física são mais afins,

${ }^{4}$ Parte do material empírico, como a realização das entrevistas com professores experientes do Ensino Médio da rede estadual paulista, foi realizado com apoio de bolsa de iniciação científica fomentada pelo CNPq entre 2010 e 2011, no contexto do PIBIC/UNICAMP.

${ }^{5}$ Disponível em: <http://www.educacao.sp.gov.br/portal/projetos/sao-paulo-faz-escola>. Acesso em: 30 jul. 2014. 
todas versam sobre "Por que ensinar Biologia?", "Por que e para que aprender Física hoje?", "Por que ensinar Química hoje?”. E, também, "Como e o que ensinar em Biologia?", "O que ensinar em Física?”, “O que deve ser estudado em Química”. Já na disciplina de Matemática, os temas são: "Ensinar Matemática", "A presente proposta" e "O que e como ensinar Matemática". A leitura de cada proposta foi feita a partir de alguns critérios de análise que foram constituídos a partir das leituras realizadas. Foram eles: marcas discursivas acerca da identidade docente (quem é o professor imaginado pelo discurso presente nos textos das propostas?) e, marcas discursivas acerca da identidade docente disciplinar (quem é o professor de Biologia, Física, Química e Matemática imaginado pela proposta?) A partir destes critérios foram, então, selecionados alguns trechos de cada Proposta, com os quais procuro dialogar levando em conta a temática da pesquisa, ou seja: a identidade docente e a disciplina escolar.

É comum que o professor, quando formula o seu plano de trabalho, indique o que vai ensinar e não o que o aluno vai aprender. E é compreensível nesse caso que, ao final do ano, tendo cumprido seu plano, ele afirme, diante do fracasso do aluno, que fez sua parte, ensinando, e que foi o aluno que não aprendeu. (SÃO PAULO, 2008, p.15)

Existe hoje entre os educadores a consciência de que é preciso dar um significado ao que é ensinado nas aulas de Física, explicitando seu sentido já no momento do aprendizado, na própria escola média. Ao mesmo tempo em que essa consciência aflora frente a tantas solicitações, dimensões e recomendações a serem simultaneamente contempladas, os professores têm se sentido perdidos, sem os instrumentos necessários para as novas tarefas, sem orientações mais concretas em relação ao que fazer.” (SÃO PAULO, 2008, p. 43) [Proposta de Física]

Nos dois fragmentos inicialmente selecionados acima, percebe-se um professor que precisa de ajuda, pois não tem clareza do seu papel - precisa se preocupar mais com ensinar do que com aprender - e, também, se sente perdido. Nesse sentido, os Cadernos funcionam como um dispositivo de poder que pode, discursivamente, constituir um lugar de submissão para o professor.

[...] o professor não se limita a suprir o aluno de saberes, mas é o parceiro de fazeres culturais, aquele que promove de muitas formas o desejo de aprender, sobretudo com o exemplo de seu próprio entusiasmo pela cultura humanista, científica, artística e literária. (SÃO PAULO, 2008, p. 13)

Nesta situação, o desafio da escola e dos professores é romper esse círculo vicioso que acaba por afastar os estudantes desta e de outras disciplinas e superar a mera descrição dos fatos e fenômenos da Biologia, para tratar dos assuntos e temas biológicos que fazem parte da vida contemporânea e da vida dos alunos. (SÃO PAULO, 2008, p. 42) [Proposta de Biologia] 
Nesses fragmentos, é possível perceber traços da identidade docente desenhada nos documentos: um professor com um repertório cultural ampliado e entusiasta da cultura humanista.

A reunião de certos conjuntos de disciplinas em áreas do conhecimento é decorrência natural das referidas fronteiras comuns. No nosso caso, é também um recurso de sentido pedagógico, para explicitar que a aprendizagem disciplinar não tem sentido autônomo, mas deve se dar em função dos interesses dos alunos, de sua formação geral. Nesse sentido, a área constitui uma pré-articulação de um sistema mais amplo, o projeto pedagógico de escola, em que a proposta curricular organiza e dá razões para a aprendizagem em geral, disciplinar ou não. (SÃO PAULO, 2008, p. 36)

Para que uma aprendizagem significativa seja alcançada, é necessário o envolvimento ativo dos alunos nesse processo. Essa participação efetiva requer que o professor dê voz ao aluno, conhecendo o que ele pensa, como enfrenta as situações-problema propostas e, num processo dialógico, o auxilie na re-elaboração de suas ideias. (SÃO PAULO, 2008, p. 45) [Proposta de Química]

É importante que se atente para a necessidade de incorporar o trabalho com a geometria em todos os sete anos da grade escolar, cabendo ao professor a escolha da distribuição mais conveniente dos conteúdos nos bimestres, assim como o viés que será dado ao tratamento dos temas da geometria (São Paulo, 2008, p. 46, Proposta de Matemática). Reiteramos que, na presente proposta, o professor dê especial atenção ao planejamento sobre 'o que', 'como' e 'com que grau de profundidade' irá abordar os conteúdos sugeridos na grade bimestral. (SÃO PAULO, 2008, p. 480) [Proposta de Matemática]

Numa análise mais detalhada dos documentos chamados Cadernos do Professor, é possível notar algumas diferenças no desenho da identidade docente constituída. É importante lembrar que examinamos os discursos das equipes disciplinares a partir da noção de discurso proposta por Foucault, que a enuncia como "conjunto dos saberes e práticas que formam sistematicamente os objetos de que falam” (FOUCAULT, 2002, p. 56). As equipes de Biologia e Química possuem discursos mais próximos, estas estão mais preocupadas em direcionar os professores para o desenvolvimento pedagógico, propondo, sugerindo ou, até mesmo, impondo atividades que auxiliem os professores a trabalhar os conteúdos em sala de aula. O diálogo da equipe de Biologia com os professores de Biologia tem um tom mais impositivo, como se estivesse coordenando, mesmo, as atividades do professor em sala de aula com palavras como: Faça, peça, avalie, termine etc.; são poucas as expressões de tom auxiliador como: sugerimos que, propomos que etc., como no trecho abaixo, presente no Caderno do professor: biologia, Ensino Médio $-1^{a}$ série, $2^{\circ}$ bimestre, 
Inicialmente, peça aos alunos para confrontarem suas representações iniciais com as novas informações e sistematize os conceitos principais. (SÃO PAULO, 2008, p. 27)

Percebe-se a imagem de um professor que precisa ser coordenado e que depende de orientações concretas para o desenvolvimento dos conteúdos. Já a equipe de Química tem um tom mais auxiliador, utilizando expressões como: O professor pode fazer, O professor pode pedir, $O$ professor pode avaliar, O professor pode terminar etc., como mostra o trecho abaixo, do Caderno do professor: química, Ensino Médio - $1^{\mathrm{a}}$ série, $1^{\mathrm{o}}$ bimestre,

O professor poderá iniciar a aula com o levantamento das ideias dos estudantes sobre quais materiais eles consideram mais importantes para a sociedade moderna. (SÃO PAULO, 2008, p. 30)

O professor pode perguntar também se os alunos sabem o que é temperatura de ebulição. (SÃO PAULO, 2008, p. 35)

Aqui se desenvolve a imagem de um professor que necessita de auxílio para desenvolver os conteúdos e preocupado com os conhecimentos prévios dos alunos. Nos Cadernos do Professor de Física, aparecem muitas atividades que fazem o professor trabalhar de forma mais próxima ao cotidiano dos alunos, explorando os conteúdos de física com temas e atividades lúdicas que fazem parte do dia a dia do aluno. A equipe de Física também dialoga com os professores de Física da mesma forma que a equipe de Biologia, com um tom mais impositivo.

Peça aos alunos que, em grupos, façam o estudo deste gráfico. (SÃO PAULO, 2008, p. 27) [Caderno do professor: física, Ensino Médio - $2^{\mathrm{a}}$ série, $4^{\circ}$ bimestre]

Inicie a aula falando de iluminação de lojas. (SÃO PAULO, 2008, p. 31) [Caderno do professor: física, Ensino Médio - $2^{\mathrm{a}}$ série, $4^{\circ}$ bimestre]

As evidências discursivas permitem afirmar que o professor de Física é dependente de orientações concretas e coordenado o tempo todo. Nos Cadernos do Professor de Física, também percebe-se que o conhecimento cientifico aparece por meio de um campo de linguagem, buscando considerar o cotidiano do aluno, onde são introduzidos conceitos gerais dos conteúdos de Física, por exemplo no trecho abaixo:

Assim, ao se tratar da percepção das cores, o cérebro tem um papel importantíssimo em tudo que vemos. Com isso, é preciso deixar claro que a percepção das cores depende, então, de propriedade dos objetos e da luz que incide sobre eles, bem como das características de funcionamento de nossos olhos, de nosso sistema nervoso e de nosso cérebro. (SÃO PAULO, 2008, p. 28) [Caderno do professor: física, Ensino Médio - $2^{\mathrm{a}}$ série, $4^{\circ}$ bimestre] 
Uma boa forma de iniciar a aula é perguntar aos alunos sobre o telefone celular. Pergunte quanto deles têm, quanto tempo utilizam, como o usam, com qual frequência etc. Muitos alunos chegam a afirmar que não poderiam viver sem ele. (SÃO PAULO, 2008, p. 47) [Caderno do professor: física, Ensino Médio $-2^{\mathrm{a}}$ série, $4^{\mathrm{o}}$ bimestre]

Já nos cadernos do Professor de Matemática, os discursos são muito distintos dessas três equipes. Nestes, a equipe de Matemática dá muita importância em ensinar o conteúdo ao professor, indicando um professor que não domina os conteúdos. Em nenhum momento, os cadernos propõem metodologias ao professor para o desenvolvimento dos conteúdos.
É desejável que o professor tente contemplar todas as oito unidades, uma vez que, juntas, compõe um panorama do conteúdo do bimestre, e muitas vezes, umas das unidades contribui para a compreensão das outras. (São Paulo, 2008, p. 8) [Caderno do professor: matemática, Ensino Médio $-1^{a}$ série, $3^{\circ}$ bimestre]
Os logaritmos foram criados no inicio do século XVII, com o objetivo de simplificar cálculos. (SÃO PAULO, 2008, p. 20) [Caderno do professor: matemática, Ensino Médio - $1^{\text {a }}$ série, $3^{\circ}$ bimestre]

Para o discurso que indica como a disciplina se relaciona com a área, em nenhum momento se percebe um diálogo das equipes direcionando os professores em tratar as disciplinas como parte de uma área do conhecimento. Assim, o discurso da Proposta Curricular sobre integração das disciplinas da mesma área não é repetido nos Cadernos do Professor. Foi observada, uma vez, no Caderno de Biologia, uma proposta para que o professor de Biologia trabalhe um dos conteúdos com os professores de História e Geografia, apesar de estas fazerem parte de outra área.
Proponha um desafio, expondo a próxima situação de aprendizagem cuja situação se refere ao Brasil e sugere uma aprendizagem interdisciplinar com Historia e/ou Geografia. (SÃO PAULO, 2008, p. 29) [Caderno do professor: biologia, Ensino Médio $-1^{\mathrm{a}}$ série, $2^{\circ}$ bimestre]

Com relação a esses materiais investigados, foi possível depreender que a circularidade de discursos está presente de forma múltipla, no entanto, há sempre a manutenção da identidade docente disciplinar.

\section{O contato com o cotidiano escolar e as narrativas docentes}

Ao se estudar a circularidade entre políticas curriculares oficiais e fazeres pedagógicos cotidianos, optou-se pelas narrativas como método. Foram ouvidas histórias daqueles que, nas brechas de suas memórias, podem oferecer-nos imagens de um tempo e de um lugar. 
Na perspectiva de Benjamin (1994a), a narrativa encontra-se intimamente relacionada ao ato de rememorar, a possibilidade de ressignificação da própria experiência por meio das memórias cheias de significados, sentimentos e sonhos. $\mathrm{O}$ ato de rememorar possibilita que dimensões pessoais, que foram perdidas com o avanço do mundo moderno e capitalista, sejam recuperadas na relação temporal passado, presente e futuro. Trabalhar com narrativas é trabalhar com aberturas, com a possibilidade de interlocuções com outros, sem procurar responder a todas as perguntas, muitas vezes, até criando outras. A arte da narrativa está em evitar explicações sobre o dito, permitindo que o leitor fique livre para interpretar o narrado como quiser, podendo este atingir uma amplitude que não existe na informação. $\mathrm{O}$ narrador benjaminiano traz consigo a característica do saber aconselhar, o que torna a experiência vivida significante e potencializante, sendo este aconselhamento entendido menos como uma forma de saber responder perguntas, mas em dar sugestões.

Para Michel de Certeau (1994), ao falarmos ou ao narrarmos, estamos praticando uma arte, e essa produz efeitos. Assim, o narrar não seria um retorno à descrição, mas um ato que procura, distanciando-se cautelosamente da realidade, provocá-la. Nas palavras do autor: "mais que descrever um "golpe", ela (a narrativa) o faz" (CERTEAU, 1994, p. 154). E ao fazer o golpe, ao praticar a astúcia, essa arte pode assumir múltiplos desdobramentos. Sendo arte, exige criação; sendo astuta, pode se engendrar com ousadia (CERTEAU, 1994; JOSGRILBERG, 2005).

Foram entrevistados cinco professores de Ensino Médio de uma escola pública estadual, que tem exercício profissional na área das Ciências da Natureza. Os perfis dos entrevistados são apresentados a seguir: professora de Biologia - 18 anos de experiência docente, trabalha na escola estadual e, também, em escola particular; professor de Física - 15 anos de experiência docente, trabalha em diferentes escolas públicas estaduais; professor de Matemática - vinte anos de experiência docente, trabalha como professor efetivo na escola; professora de Matemática - 19 anos de experiência docente, trabalha como professora efetiva na escola; professora de Química - vinte anos de experiência docente, trabalha como professora efetiva na escola e, também, como orientadora pedagógica em escola municipal de Ensino Fundamental. Todos os entrevistados são licenciados nas disciplinas escolares nas quais atuam.

As entrevistas foram gravadas em áudio, transcritas, textualizadas e, para fins analíticos, transformadas em mônadas, que são fragmentos de narrativas conforme descrito em Petrucci -Rosa et al. (2011), que serão apresentadas a seguir.

As mônadas são pequenas histórias extraídas das entrevistas narrativas. A palavra mônada significa, em Leibniz, “a unidade das coisas”. São partes-todo, à medida que, num fragmento, têm o poder de retratar um cenário mais amplo e geral de acontecimentos e experiências. A noção de mônada vem da forma como Benjamin (1994) escreveu o texto "A Infância em Berlim por volta de 1900", no qual, já adulto, narra seu tempo de criança, por meio de historietas cheias de significado (PETRUCCI-ROSA et al., 2011).

Do ponto de vista metodológico, opera-se com a transcrição das entrevistas, extraindo fragmentos que dialogam com as questões de investigação. Ao se realizarem as entrevistas, as seguintes perguntas foram colocadas: Como é sua experiência com a disciplina escolar que você ensina? Como tem sido sua experiência com a Proposta Curricular do Estado de São Paulo, de 2008, e seus materiais didáticos? Há possibilidades de trabalho interdisciplinar em sua prática? 


\section{Mônada 1}

\section{Fechando o professor}

O Caderno - também chamado de "caderninho" - não é para ser seguido como uma "biblia". Ele é uma orientação, um apoio. Então, com "caderninho" ou sem "caderninho", dá para faz̧er um trabalho interdisciplinar. Não acredito que esse "caderninho" ou a coordenação da escola impossibilite a realização de um trabalho interdisciplinar! Não acredito nisso não! Dápara fazer tranquilamente. Assim, talvez se eu olhar esse Caderno com uma maior profundidade, acho que até dá para usar o próprio material para iniciar um trabalho interdisciplinar, porque está tudo ali! Resumidamente, superficialmente, mas está ali! Mas a presença deste material na escola, acabou fechando o professor na sua disciplina. (Professora de Química)

\section{Mônada 2}

\section{Coisas boas}

Tem muitas coisas boas nesta Proposta, mas tem que saber trabalhar. Não precisa seguir à risca também. Você tem que escolher alguma coisa para ver o que será possivel trabalhar com seu aluno. Porque a única pessoa que conhece o seu aluno, é você que está na sala de aula todo os dias. Tenho três primeiros anos aqui, mas não consigo trabalhar o mesmo conteúdo nas três salas iguais. (Professora de Matemática)

\section{Mônada 3}

\section{Vai estar no mesmo conteúdo}

Isso facilitou porque, antes se você recebia um aluno de uma cidade pequenininha distante, ele estava tendo uma outra matéria completamente diferente. Então, ele entrava na sala e não sabia do que eu estava falando. Agora pelo menos está tendo a mesma coisa. Seria bom se todos os professores seguissem o Caderno. Se o aluno sai daqui e vai estudar em Presidente Prudente, por exemplo, ele vai estar no mesmo conteúdo. Isso não acontecia antes. Achei bom, porque unificou o conteúdo. Os alunos são muito itinerantes, mudam muito. Hoje eles estudam durante um mês aqui, no mês que vem, estão em outra cidade... (Professora de Matemática)

\section{Mônada 4}

\section{Participação}

Penso que os professores deveriam ter uma participação nessa elaboração. Será que os professores que trabalham em sala de aula participaram disto? Será que os professores autores estão em sala de aula, hoje, com 40 alunos? (Professora de Matemática)

\section{Mônada 5}

\section{Para que serve?}

Acho interessante o "caderninho", mas, eles [os alunos] acham muito difícil. Insisto assim mesmo com eles, procurando ajudar. Abordo atividades em forma de trabalho, em dupla, para eles poderem entender melhor. Coloco uma situação de aprendizagem para eles e questiono: para que serve? Pego algumas questões de situação de aprendizagem, e aplico para eles. Agora, eles acharam a trigonometria mais interessante, no sentido de usar seno e cosseno na situação de aprendizagem, das marés, das várias situações que envolvem a trigonometria. Mas aí, tem aqueles que não sabem achar o seno zero de noventa, entendeu? Então o "caderninho" para mim tem sido bom, até porque não tem como ficar o tempo todo escrevendo na lousa. Com o "caderninho" dá para visualizar legal. No caso da trigonometria, possibilita enxergar melhor. Então eles tem mais visão da parte gráfica... (Professor de Matemática) 


\section{Mônada 6}

\section{Nunca ninguém veio me orientar}

Os Cadernos influenciaram muito pouco... Há falhas na entrega dos Cadernos, pois o ano tem início e eles não chegam. Os Cadernos do $1^{\circ}$ bimestre vão chegar no $2^{\circ}$ bimestre, o do $2^{\circ}$ bimestre vai chegar lá no $3^{\circ}$. Então não existe compromisso nesse sentido, não existe a responsabilidade no sentido de dizer de que forma devem se usar os Cadernos. Nunca ninguém veio me orientar. Não que eu tenha necessidade disso, mas a partir do momento que se lança a Proposta, penso que isso é fundamental: que você tenha grupos de pessoas que elaboraram o projeto que venham discutir como usar, como trabalhar esse projeto. Isso nunca aconteceu. (Professor de Física)

\section{Mônada 7}

\section{Só direcionar}

Mudou a dependência deles em relação a mim como professora, pois antes eu falava um monte de coisas aqui na frente, discutia, ouvia a participação deles, questões, dúvidas, coisas que eles viram ou ficavam sabendo e questionavam. Quando chegou o "caderninho", tinha determinados assuntos que eu não podia fazer uma exposição na frente. Tinha só que direcionar: "então gente hoje vocês vão ler um texto que fala sobre isso..." Era o máximo que podia falar para eles. Ai eles liam o texto interpretavam as questões e a gente ia para a segunda parte. Isso seria uma aula expositiva ou qualquer outra coisa que você venha a ter na escola. Se você tiver outra fonte de informação que não seja só aula expositiva, dá para usar. Mas fica difícil! Eu acho que o aluno não está acostumado, trabalha muito diferente. (Professora de Biologia)

\section{Mônada 8}

Zero

Não tem interdisciplinaridade: zero! Até porque a questão da interdisciplinaridade é muito mal compreendida nas escolas. Interdisciplinaridade implica em você trabalhar em grupos. Isso não existe! Aquele que fala que faz interdisciplinaridade, não vou dizer que não tem ideia do que é isso, mas na maioria das escolas compreende-se de forma totalmente incorreta. Interdisciplinaridade não é você dar um assunto, como por exemplo: na Física. Aí, pega uma reportagem sobre História, coloca no item do livro de física, dá para o aluno e fala que está faz̧endo interdisciplinaridade. Isso não é interdisciplinaridade, isso implica primeiramente num esforço muito grande por parte de cada professor e por parte do grupo. Então, se você não tem um grupo para trabalhar a interdisciplinaridade, você não faz interdisciplinaridade. Não faço interdisciplinaridade e ninguém aquifaz: (Professor de Física)

\section{Mônada 9}

\section{Não foi muito legal}

Interagir com outro professor, não acho que nem aqui nem em outro colégio, não consegui ainda! É difícil, porque às vezes você vai falar com o professor, para ver se pode fazer alguma coisa juntos e ele diz: "ah! mas o meu conteúdo está sendo outro! Então, não vai dar!” Não consegui ainda. Também só tentei uma vez. só falar sobre isso, mas depois vi que a resposta não foi muito legal, não insisti mais nos outros bimestres. (Professor de Matemática) 


\section{Mônada 10}

\section{Dá para você trabalhar?}

Estou trabalhando, no primeiro ano, com gráficos que envolvem porcentagem e probabilidade e os alunos, na minha aula, tem que montar um gráfico. Você pode entender que, o professor de Matemática está trabalhando isso também. A impressão que dá, que o aluno vai lá e pergunta para o professor de Matemática ou então en tenho que chegar epedirpara ele: "Dápara vocêfazer tal coisa na sala de aula? Dá para você trabalhar com probabilidade com eles? Dá para você trabalhar com porcentagem com eles?” (Professora de Biologia)

A leitura das mônadas evidencia usos e consumos dos documentos curriculares nas práticas escolares dentro das disciplinas da área de Ciências da Natureza. Compreende-se como documentos curriculares aquilo que os professores chamam de "Proposta", "Caderno", "Caderninho", porque neles estão os discursos instituídos pela política pública para um "novo" currículo de Ensino Médio, no Estado de São Paulo, a partir de 2008. Nas práticas curriculares narradas, é possível perceber, pelo menos, dois movimentos: o primeiro relativo aos usos e consumos a partir da disciplina escolar e, por último, as dificuldades expressas relacionadas com as possibilidades de integração curricular como interdisciplinaridade.

Em relação aos usos e consumos (CERTEAU, 1994) que são feitos da Proposta Curricular para o Ensino Médio (SÃO PAULO, 2008), os professores narram aspectos relacionados com a padronização dos conteúdos e, também, em relação às metodologias empregadas em sala de aula. A padronização dos conteúdos acaba configurando um dilema, pois a mesma professora afirma que se trata de uma medida promissora, ao mesmo tempo que apaga as diferenças entre os alunos. As metodologias de ensino são desnaturalizadas no contato com o material didático dos Cadernos. Esse é um efeito importante que o material parece produzir, desestabilizando identidades docentes. Os Cadernos acabam sendo dispositivos que produzem formas de ser-professor marcadas por uma constante inquietação. Os Cadernos e a Proposta Curricular como documentos curriculares instituídos não provocam implementações acríticas e desproblematizadas. Ao contrário, como Certeau afirma em relação ao cotidiano, todo consumo é ativo e permeado por táticas que transformam aquilo que a ordem instituída imaginou.

Quanto à interdisciplinaridade, como forma de integração curricular, é interessante perceber, nas narrativas, as tensões presentes no cotidiano escolar, a partir de uma gama de possibilidades de entendimento do que seja trabalhar de forma interdisciplinar. Os professores narradores entendem essa modalidade de trabalho pedagógico como ação coletiva e se sentem enclausurados na disciplina escolar no contato com os Cadernos. Esse esboço de resistência é muito interessante e mostra um caminho de pesquisa instigante que pode ser explorado.

\section{Últimas considerações}

Articulando a noção de identidade docente (HALL, 2003; PETRUCCI-ROSA, 2007) com as práticas expressas pelas narrativas dos professores a partir das políticas da SEE/SP, foi possível perceber que, apesar de existir, nos documentos, um tom mais prescritivo para o professor, "ordenando" suas ações e deixando claro que sua capacidade está aquém do necessário, as possibilidades de ação pedagógica são transformadas. 
Os professores narram práticas pedagógicas que podem prescindir do Caderno do Professor, ou, então, experiências que se pautam no uso do material de forma mais criativa. As relações de pertencimento próprias da comunidade docente parecem estar sendo ressignificadas no contato com os discursos presentes nos textos curriculares. Em especial, na mônada 7, notase a evidência de um reposicionamento da identidade docente na relação com o Caderno do Professor, à medida que a professora de Biologia conta que seu papel está sendo reconfigurado em sala de aula na interação com os alunos.

Como já mencionado, diferentes equipes formularam os Cadernos do Professor em cada disciplina escolar da área estudada. Por isso, as identidades docentes prescritas nos textos são também imaginadas de diferentes formas. Em Matemática, por exemplo, o texto curricular se propõe a ensinar conteúdos ao professor, abrindo mão de qualquer orientação didáticometodológica.

De uma maneira geral, tanto os discursos presentes nos textos como as narrativas docentes indicaram um isolamento do trabalho pedagógico no interior de cada disciplina escolar, sem a emergência de relações de pertencimento na área de Ciências da Natureza e Matemática, nem tampouco interações com outras áreas.

No entanto, por outro lado, os resultados da pesquisa também mostraram que não há uma resistência mais crítica, ou algum tipo de boicote ao uso do material didático que representa a reformulação curricular; enquanto os discursos presentes nesses textos estão se configurando dispositivos importantes para a desestabilização e para a criatividade docente. À medida que os docentes concordam ou discordam do que está prescrito no texto, eles são interpelados a reinventar suas práticas, criando "novas" formas de fazer que são, ao mesmo tempo, híbridas e recontextualizadas (LOPES, 2005).

\section{Referências}

BENJAMIN, W. Obras escolhidas: magia e técnica, arte e política. 7. ed. São Paulo: Brasiliense, 1994a.

. Infância em Berlim por volta de 1900. In: Obras escolhidas II: rua de mão única. São Paulo: Brasiliense, 1994b. p. 73-142.

BRASIL. Ministério da Educação. Parâmetros curriculares nacionais: Ensino Médio. Brasília: MEC: SEMT, 1999. $4 \mathrm{v}$.

CERTEAU, M. A invenção do cotidiano: artes de fazer. Petrópolis: Vozes, 1994.

FOUCAULT, M. A arqueologia do saber. 6. ed. Rio de Janeiro: Forense Universitária, 2002.

GOODSON, I. Currículo: teoria e história. Petrópolis: Vozes, 1995.

HALL, S. A identidade cultural na pós-modernidade. Rio de Janeiro: DP\&A, 2003.

JOSGRILBERG, F. B. Cotidiano e invenção: os espaços de Michel de Certeau. São Paulo: Escrituras, 2005.

LOPES, A. C. Discursos curriculares na disciplina escolar química. Ciência \& Educação, Bauru, v. 11, n. 2, p. 263-278, 2005. 
MARIN, A. J. Formação de professores: novas identidades, consciência e subjetividade. In: TIBALDI, E. F. A.; CHAVES, S. M. (Org.). Concepções e práticas em formação de professores: diferentes olhares. Rio de Janeiro: Alternativa: DP\&A, 2002. p. 57-73.

MOREIRA, A. F. B.; FERREIRA, M. S. A história da disciplina escolar ciências nas dissertações e teses brasileiras no período 1981-1995. Ensaio: pesquisa em educação em ciências, Belo Horizonte, v. 3, n. 2, p. 133-144, 2001.

PETRUCCI-ROSA, M. I. P. Experiências interdisciplinares e formação de professore(a)s de disciplinas escolares: imagens de um currículo-diáspora. Pro-posições, Campinas, v. 18, n. 2, p. 51-65, maio/ago., 2007.

PETRUCCI-ROSA, M. I. P. et al. Narrativas e mônadas: potencialidades para uma outra compreensão de currículo. Currículo sem Fronteiras, v. 11, n. 1, p. 198-217, jan/jun. 2011. Disponível em: $<$ http://www.curriculosemfronteiras.org/vol11iss1articles/rosa-ramos-correa-junior.pdf $>$. Acesso em: 30 jul. 2014.

SÃO PAULO (Estado). Secretaria Estadual de Educação. Proposta curricular do

estado de São Paulo. São Paulo: SEE, 2008. Disponível em: <http://www.rededosaber.

sp.gov.br/portais/spfe2009/MATERIALDAESCOLA/PROPOSTACURRICULAR/

ENSINOFUNDAMENTALCICLOIIEENSINOM\%C3\%89DIO/tabid/1252/Default.aspx>. Acesso em: 30 jul. 2014.

SOUZA JÚNIOR, M.; GALVÃO, A. M. O. História das disciplinas escolares e história da educação. Educação e Pesquisa, São Paulo, v. 31, n. 3, p. 391-408, 2005. 